\title{
Antibacterial and Antifungal Potentiality of Leaf Extract of Phyllanthus Fraternus Webster: An Ethnomedicinal Plant
}

\author{
Kavit Mehta ${ }^{1, *}$, Patel B.N ${ }^{1}$, Jain B. $\mathrm{K}^{2}$ \\ ${ }^{1}$ Mehsana Urban Institute of Science, Ganpat University, Kherwa, Dist. Mehsana, North Gujarat \\ ${ }^{2}$ M. G. Science Institute, Dadasaheb Mavlankar Campus, Navarangpura, Ahmedabad \\ *Corresponding author: kavitmehtabiotech@gmail.com
}

Received March 04, 2014; Revised March 28, 2014; Accepted March 312014

\begin{abstract}
Phyllanthus fraternus Webster is a medicinally very useful plant species used by tribal of Gujarat, India to cure certain diseases like asthama, cough, diarrohea and scabies. Methanolic and ethanolic leaf extracts of the plant leaf were evaluated against eleven clinically important bacterial strains such as $E$. coli, B. megaterium, $B$. cereus, B. subtilis, C. glutamicum, S. aureus, S. typhi, S. typhi A, S. typhi B, P. aeruginosa and P. vulgaris and one fungal strain namely $A$. niger by disc diffusion method. Result showed maximum antibacterial activities against $C$. glutamicum with zone of inhibition of $40 \mathrm{~mm}$ and minimum against $S$. typhi A with zone of inhibition of $15 \mathrm{~mm}$ in methanol extract. In ethanol extract maximum antibacterial activities were reported in Bacillus cereus with zone of inhibition of $21 \mathrm{~mm}$ and minimum against Salmonella typhi $A(10 \mathrm{~mm})$. The maximum antifungal activity was noted against $A$. niger $(40 \mathrm{~mm})$. Our preliminary phytochemical analysis of leaf extract using Methanol as solvent confirmed the presence of alkaloids, tannin, saponin, terpenoid and steroids. This indicates that antimicrobial activities may be due to presence of secondary metabolites. Hence, the plant can be used to discover bioactive natural products that may serve as leads in the development of new pharmaceuticals research activities.
\end{abstract}

Keywords: alkaloid, bioactive, natural product

Cite This Article: Kavit Mehta, Patel B.N, and Jain B. K, "Antibacterial and Antifungal Potentiality of Leaf Extract of Phyllanthus Fraternus Webster: An Ethnomedicinal Plant." American Journal of Microbiological Research, vol. 2, no. 2 (2014): 74-79. doi: 10.12691/ajmr-2-2-6.

\section{Introduction}

India has rich heritage of using medicinal plants in traditional medicines. Although hundred of plant species have been tested for antimicrobial properties (Uzun et al., 2002; Ates et al., 2003; Kirbag et al., 2005; Nair, 2005; Kumar et al., 2006, Doughari et al., 2008, Kirbag et al., 2009; Dash et al., 2011; Dubey et al., 2012, Bashir et al., 2012 and Vashist and Jindal, 2012), there is no report on antimicrobial properties of various plants parts like leaves, fruit, root of Phyllanthus fraternus Webster against the bacterial and fungal microorganisms. The present study is aimed to carry out the preliminary phytochemical analysis and to screen in vitro antimicrobial activity of the leaf extract against eleven clinically important bacterial strains and one fungal strain by using agar disc diffusion method.

\section{Material and Methods}

The leaves of plant of Phyllanthus fraternus Webster were collected from Botanical garden of Ganpat University; Ganpat vidyanagar; Kherwa, North Gujarat. The plant is annual having the length of $20-50 \mathrm{~cm}$. It

produces pale greenish -yellow colored axillary flowers. The seeds are trigonous.

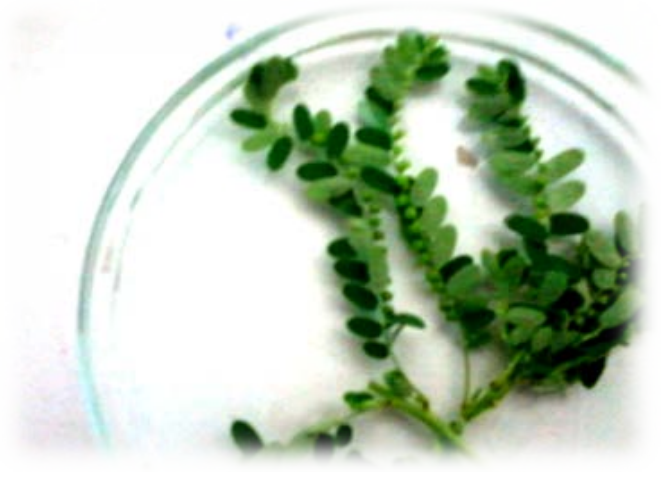

Figure 1. A twig of Phyllanthus fraternus

\subsection{Extraction of Plant Leaves}

The extraction of leaves was done by methanol by using Soxhlet apparatus. The solvent was evaporated by using rotary evaporator at $80^{\circ}$ temperature and the extract obtained was cooled and dried under vacuum.

\subsection{Phytochemical Screening}


Chemical tests were carried out on the aqueous extract and on the powdered specimens using standard procedures to identify the phytoconstituents as described by Harbone (1973), Sofowara (1979) and Trease and Evans (1983).

\subsection{Determination of Constitutes by TLC}

For TLC analysis plates of $10 \times 10 \mathrm{~cm}$ size with aluminum support silica gel $60 \mathrm{~F}_{254}$, (Merck) were cut with ordinary household scissors. Plate markings were made with soft pencil. Plates were impregnated by dipping into $4 \%$ solution of sodium acetate in methanol -water (3:2) for 5 second followed by drying at room temperature for 1 hr .Glass capillaries were used to spot the sample Plates were developed vertically in a CAMAG twin trough chamber previously saturated with Toluene-ethyl acetatediethylamine (7:2:1) mobile phase for $20 \mathrm{~min}$. After the run, plates were dried and dragndorff reagent was sprayed at room temperature for detection of active compounds.

\subsection{Determination of Constitute by HPTLC}

HPTLC was performed on $20 \mathrm{~cm} X 10 \mathrm{~cm}$ aluminum plates pre-coated with $0-2 \mathrm{~mm}$ layer of silica gel $60 \mathrm{~F}_{254}$ (Merck, Germany). Samples were applied in band with a Linomat 5 applicator, CAMAG (Switzerland) equipped with a $100 \mathrm{uL}$ syringe. Plates were developed vertically in a CAMAG twin trough chamber previously saturated with Toluene-chloroform-ethanol (4:4:1) mobile phase vapour for 20 minutes at room temperature.

The CAMAG TLC Scanner, controlled by winCATS software was used for densitometry analysis. Densitometry analysis was carried out under UV (at 256,366 and $540 \mathrm{~nm}$ ) using CAMAG TLC Scanner and spraying with solution followed by heating at $110^{\circ} \mathrm{C}$ for 1 hr under observation.

\subsection{Bacterial and Fungal Strains Used:}

Microbial strains Escherichia coli, Bacillus megaterium, Bacillus cereus, Bacillus subtilis, Cornynebacterium glutamicum, Staphylococcus aureus, Salmonella typhi, Salmonella typhi A, Salmonella typhi B, Pseudomonas aeruginosa, Proteus vulgaris, Candida albican and fungal strain Aspergillus niger and Candida albicans were obtained from MUIS, Ganpat university, Mehsana and M. G. Science institute, Ahmedabad (Gujarat).

\subsection{Antimicrobial Assay for Disc Diffusion Method}

Antimicrobial assay of solvent extracts were performed by Disc diffusion method. For bacteria Nutrient broth and for fungi Potato dextrose broth were used and $\mathrm{pH}$ was adjusted to 7.2 and 7.0 respectively with $5 \mathrm{M}$ sodium hydroxide. Bacteria and fungi were swab separately on the Nutrient agar plate and Potato dextrose agar plate respectively aseptically. The sterile disc, $5 \mathrm{~mm}$ in diameter, is saturated at concentration of $10 \mathrm{ul} / 10 \mathrm{ml}$ test culture methanolic extract and ethanolic extract. Disc with absolute methanol and ethanol is used as a control. The bacterial plates were incubated at $37^{\circ} \mathrm{C}$ for $24 \mathrm{hr}$ while fungal plates were incubated at $28^{\circ} \mathrm{C}$ for $24-48 \mathrm{hr}$. The sterile impregnated disc with plant extract were placed on the agar surface with flamed forceps and gently pressed down to ensure complete contact of the disc with the agar surface.

Antibacterial and antifungal activity was determined by measuring the diameter of the zone of inhibition surrounding microbial growth. For each strain, controls were included that comprised pure solvents instead of the extract (Parekh and Chanda, 2007).

Zone of diameter was showing no growth of the given organism has been reported as MIC of the test culture against Bacteria and fungi.

\section{Results}

Table 1. Analysis of phytochemicals in the leaf extract of Phyllanthus fraternus

\begin{tabular}{|c|c|}
\hline \multicolumn{2}{|c|}{ Phytochemical constitutents ( in methanolic leaf extract) } \\
\hline Alkaloids & Present \\
\hline Tannins & Present \\
\hline Saponins & Absent \\
\hline Phlobatannins & Absent \\
\hline Flavanoids & Absent \\
\hline Terpenoids & Present \\
\hline Glycosides & Absent \\
\hline Steroids & Present \\
\hline
\end{tabular}

Referance: Mehta Kavit, Patel, B.N. Jain, B. K., Research Journal of Recent sciences, 2013, 2 : 12-15

Determination of constitutes by HPTLC showed that under $256 \mathrm{~nm}$ and $366 \mathrm{~nm}$ (Figure 2A and Figure 2B) only chlorophyll was observed while after $1 \mathrm{hr}$ at $110^{\circ} \mathrm{C}$ treatment under $540 \mathrm{~nm}$ orange brown bands were observed which correspond alkaloid compounds (Figure 2C).
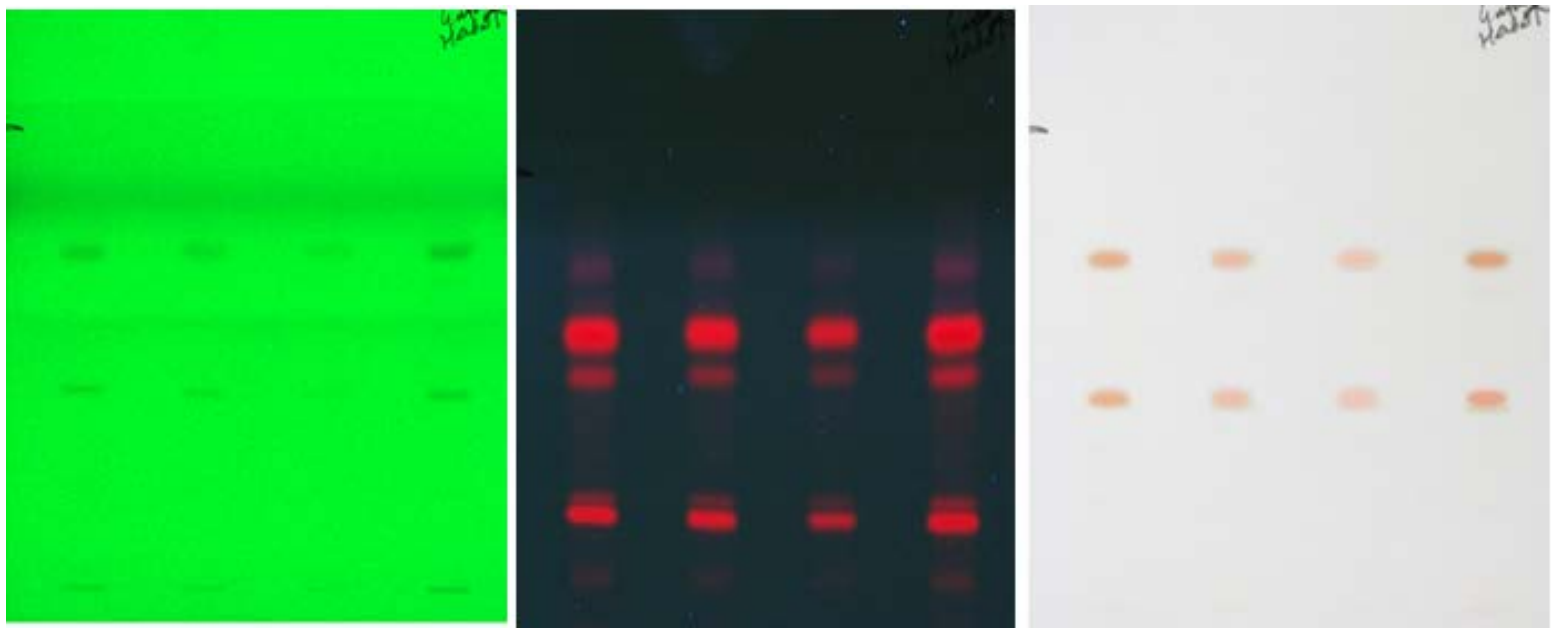

Figure 2. A: HPTLC at $256 \mathrm{~nm}, \mathrm{~B}$ : HPTLC at $366 \mathrm{~nm}, \mathrm{C}: \mathrm{HPTLC}$ at $540 \mathrm{~nm}$ 
The in vitro antibacterial and antifungal activities of methanol and ethanol extracts of leaves of Phyllanthus fraternus, in terms of zone of inhibition was presented in Table 2.

Table 2. Zone of inhibitory activity (in millimeter) of methanol and ethanol leaf extracts against microorganisms

\begin{tabular}{|c|c|c|c|}
\hline \multirow{2}{*}{ Sl.no. } & Organism & \multicolumn{2}{|c|}{ Zone of inhibition } \\
\hline \multirow{2nyy}{*}{} & \multirow{2}{*}{$\begin{array}{c}\text { Methanol } \\
\text { extract }\end{array}$} & $\begin{array}{c}\text { Ethanol } \\
\text { extract }\end{array}$ \\
\cline { 3 - 4 } & Escherichia coli & $25 \mathrm{~mm}$ & $13 \mathrm{~mm}$ \\
\hline 2. & Bacillus megaterium & $33 \mathrm{~mm}$ & $16 \mathrm{~mm}$ \\
\hline 3. & Bacillus cereus & $32 \mathrm{~mm}$ & $21 \mathrm{~mm}$ \\
\hline 4. & Bacillus subtilis & $31 \mathrm{~mm}$ & $15 \mathrm{~mm}$ \\
\hline 5. & Cornynebacterium glutamicum & $40 \mathrm{~mm}$ & $12 \mathrm{~mm}$ \\
\hline 6. & Stephylococcus aureus & $39 \mathrm{~mm}$ & $12 \mathrm{~mm}$ \\
\hline 7. & Salmonella typhi & $19 \mathrm{~mm}$ & $15 \mathrm{~mm}$ \\
\hline 8. & Salmonella typhi A & $15 \mathrm{~mm}$ & $10 \mathrm{~mm}$ \\
\hline 9. & Salmonella typhi B & $20 \mathrm{~mm}$ & $16 \mathrm{~mm}$ \\
\hline 10. & Pseudomonas aeruginosa & $18 \mathrm{~mm}$ & $11 \mathrm{~mm}$ \\
\hline 11. & Proteus vulgaris & $16 \mathrm{~mm}$ & $15 \mathrm{~mm}$ \\
\hline 12. & Aspergillus niger & $40 \mathrm{~mm}$ & No inhibition \\
\hline
\end{tabular}

\section{Discussion}

Our preliminary phytochemical screening revealed the presence of alkaloids, tannins, terpenoids and steroids in Phyllanthus fraturnus. The medicinal properties of plants are due to the presence of different complex chemical substances as secondary metabolites, which are exclusively accumulated in different parts of the plants and produce marked healing action on human body (Bashir et al., 2012). The most important of these agents are alkaloids, flavanoids and tannins (Edeoga et al., 2005). These compounds have been associated with antimicrobial effects in various studies using plant extracts (Abo et al., 1999; Newze et al., 2004 and Nwaogu et al., 2007). Plant based antibacterial compounds have enormous therapeutical potential as they can serve the purpose without side effects that are often associated with synthetic antimicrobials (Sukanya et al., 2009).

The test organisms used in the study are associated with various forms of human infections. Apart from Salmonella typhi infection, Salmonella paratyphi A and B also widely persist in Indian population (Prasannabalaji et al., 2012). In the present study methanolic and ethanolic leaf extracts of Phyllanthus fraternus showed considerable inhibitory activity against both enteric isolates of Salmonella typhi and Salmonella paratyphi. Prasannabalaji et al., (2012) have also shown that reports of such similar work on enteric Salmonella paratyphi (A and B) from scientific group is very minimal.

E. coli causes septicemias and can infect the gall bladder, meninges, surgical wounds, skin lesions and the lungs, especially in debilitate and immunodeficient patients (Doughari et al., 2008). Leaf extract of Phyllanthus fraturnus also shows high activity against $E$. coli with zone of inhibition of $25 \mathrm{~mm}$ in methanol extract but poor in ethanol extract $(13 \mathrm{~mm})$ as the inhibition zone of $14 \mathrm{~mm}$ or more considered as high antimicrobial activity (Veeramuthu et al., 2006).

From the results of present investigation it is reported that leaf extract prepared in methanol shows significant higher antimicrobial activity against all test microorganisms revealing inhibition zones between 15 $\mathrm{mm}$ and $40 \mathrm{~mm}$ as compared to that reported in ethanol leaf extract (inhibition zone ranges between $11 \mathrm{~mm}$ and 16 $\mathrm{mm}$ ) indicating that the antimicrobial activities also vary with the solvents used. This tend to show that active ingredients of the leaf are better extracted with methanol than ethanol. Eloff (1998), Ahmad et al., (1998), Lin et al., (1999), Cowan (1999) and Bashir et al., (2012) also found that methanol is more efficient than other solvents in extracting phytochemicals from plant materials. The present study ascertains the value of solvents used in the drug preparation, which could be of considerable interest to the development of new drugs. The fact that the leaf extract of Phyllanthus fraternus was active against all the tested microorganisms is also an indication that it can be a source of very potent antibiotic substances that can be used against drug resistant microorganisms. As there is no report on antimicrobial activity of leaf extract of Phyllanthus fraternus, further studies are needed to isolate and characterize the bioactive principles to develop new antimicrobial drugs.

\section{Acknowledgement}

One of the authors, B. K. Jain is thankful to University Grants Commission, New Delhi, India for providing travel grants.

\section{References}

[1] Ates A. and Erdogrul O. T. (2003). Antimicrobial activities of various medicinal and commercial plant extracts. Turk. J. Biol. 27 : 157-162.

[2] Bashir Sajid, Erum Alia, Rizwana Kausar, Saleem Uzma, Umme Ruqia-Tulain and Alamgeer (2012). Antimicrobacterial activity of some ethno-medicinal plants used in Pakistan. Res in Pharm. 2(1):42-45.

[3] Dash B. K., Faruquee H. M., Biswas S. K., Alam M. K. Sisir S. M. and Prodhan U. K. (2011). Antibacterial and antifungal activities of several extracts of Centella asiatica L. against some human pathogenic microbes. Life Sci. Med. Res. 2011: 1-4.

[4] Doughari, J. H., EI-mahmood A. M. and Tyoyina I. (2008) Antimicrobial activity of leaf extracts of Senna obtusifolia (L). Afr. J. Pharm. Pharmacol. 2(1): 07-13

[5] Dubey D., Sahu M. C., Rathi S., Bimoch P. P., Debata N. K. and Padhy R. N. (2012). Antimicrobial activity of medicinal plants used by aborigines of Kalahandi, Orissa, India against multidrug resistant bacteria. Asian Pacific J. Tropical Biomedicine. S846S854.

[6] Kumar P. V. Chauhan H. P. and Rajani M. (2006). Search for antibacterial and antifungal agents from selected Indian medicinal plants. J. Ethnopharm. 107: 182-188.

[7] Nwaogu L. A., Alisi C.s., Ibegbulem C. O. and Igwe C. U.(2007). Phytochemical and antimicrobial activity of ethanolic extract of Landolphia owariensis leaf. Afr. J. Biotech. 6 : 890-893.

[8] Prasannabalaji N., Muralitharan G., Sivanandan R. N., Kumaran S. and Pugazhvendan S. R. (2012). Antibacterial activities of some Indian traditional plant extracts. Asian Pacific J. tropical Disease. Pp.S291-S295.

[9] Vashist H. and Jindal A. (2012). Antimicrobial activities of medicinal plants- review. Inter. J. Res. Pharm. Biomed. Sci 3(1): 222-224. 


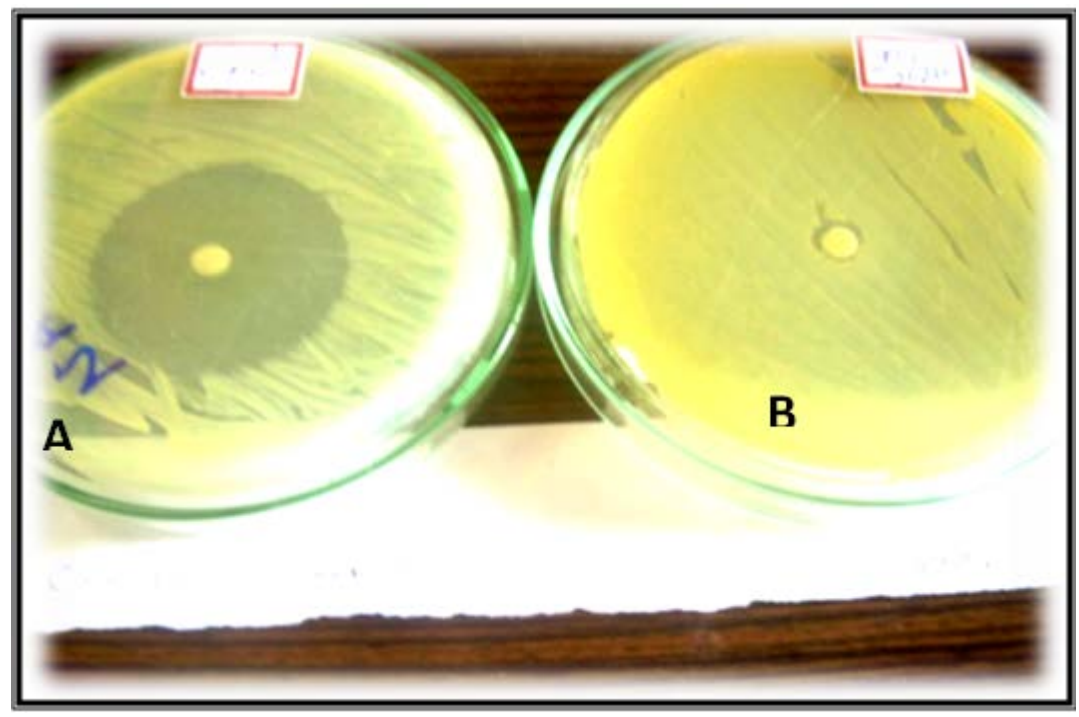

Figure 3. Zone of inhibition A: Methanol leaf extract and B: Control against C.glutamicum

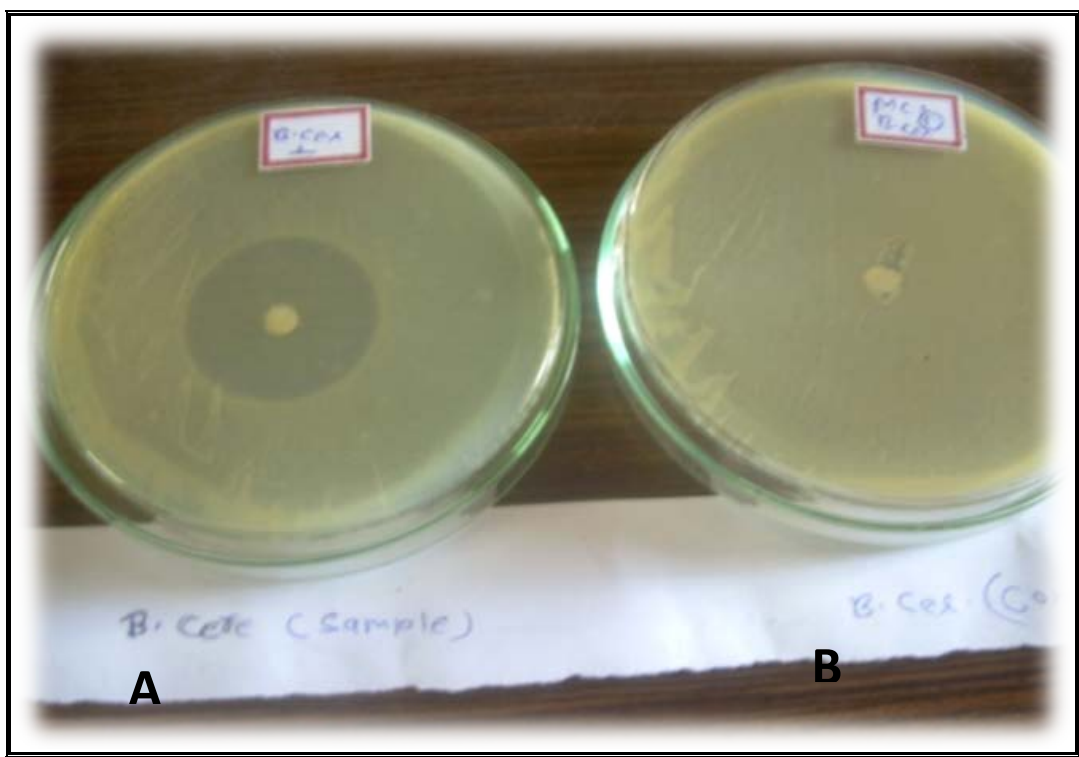

Figure 4. Zone of inhibition A: Methanol leaf extract and B: Control against B.cereus

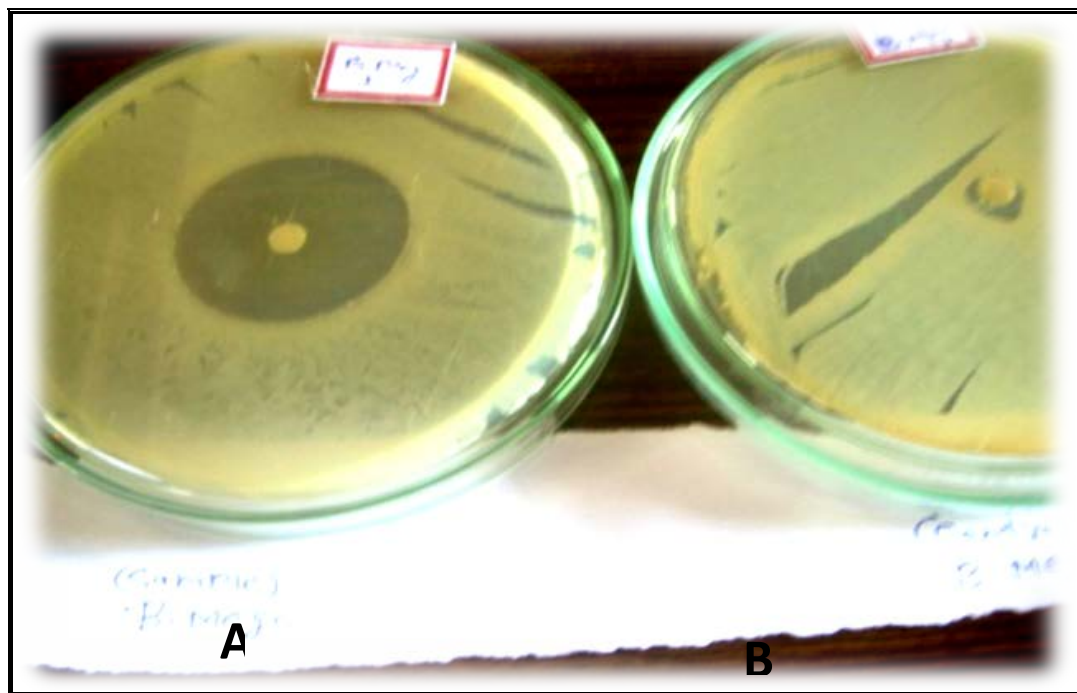

Figure 5. Zone of inhibition A: Methanol leaf extract and B: Control against B. megaterium

\section{Plate -1}




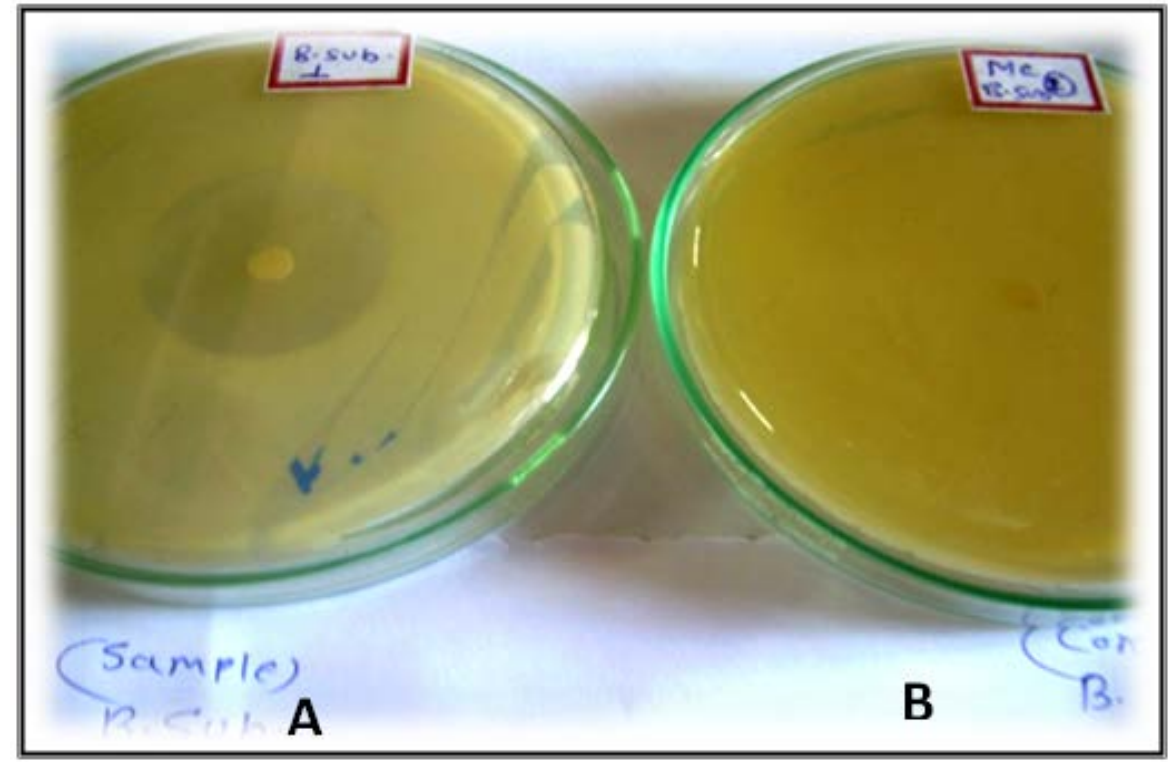

Figure 6. Zone of inhibition A: Methanol leaf extract and B: Control against B. Subtilis

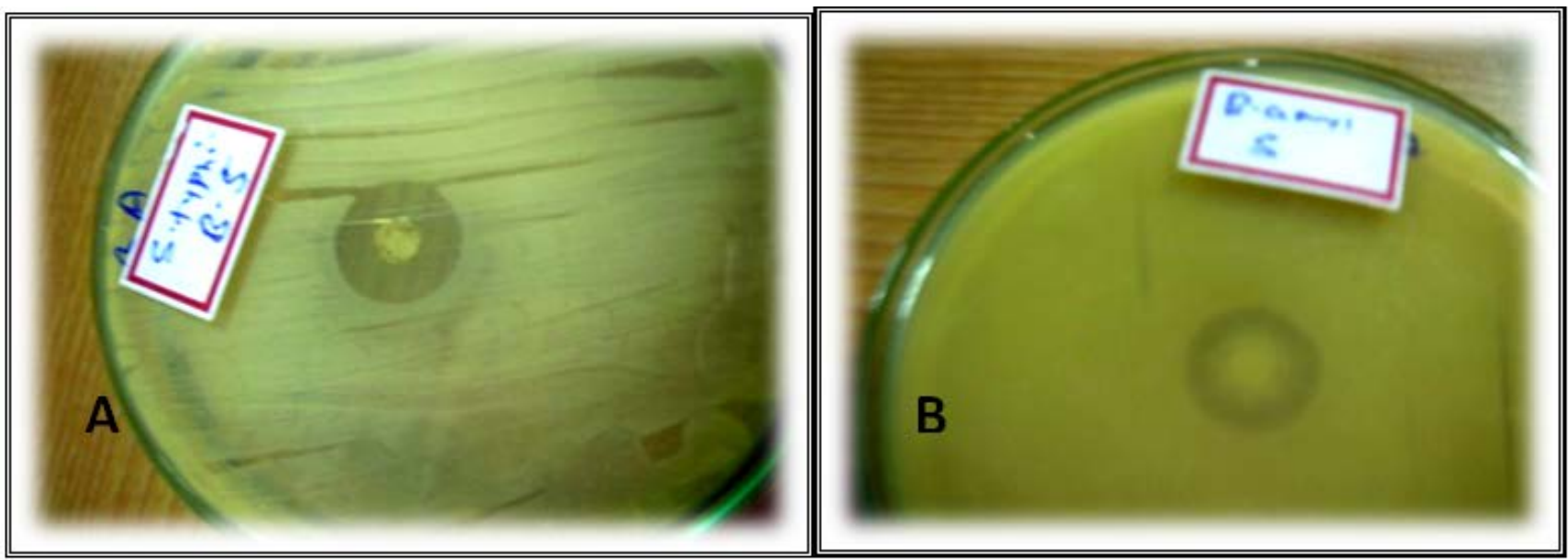

Figure 7. Zone of inhibition, Ethanol leaf extract against A: B. amyloliquefaciens and B: S.typhi B
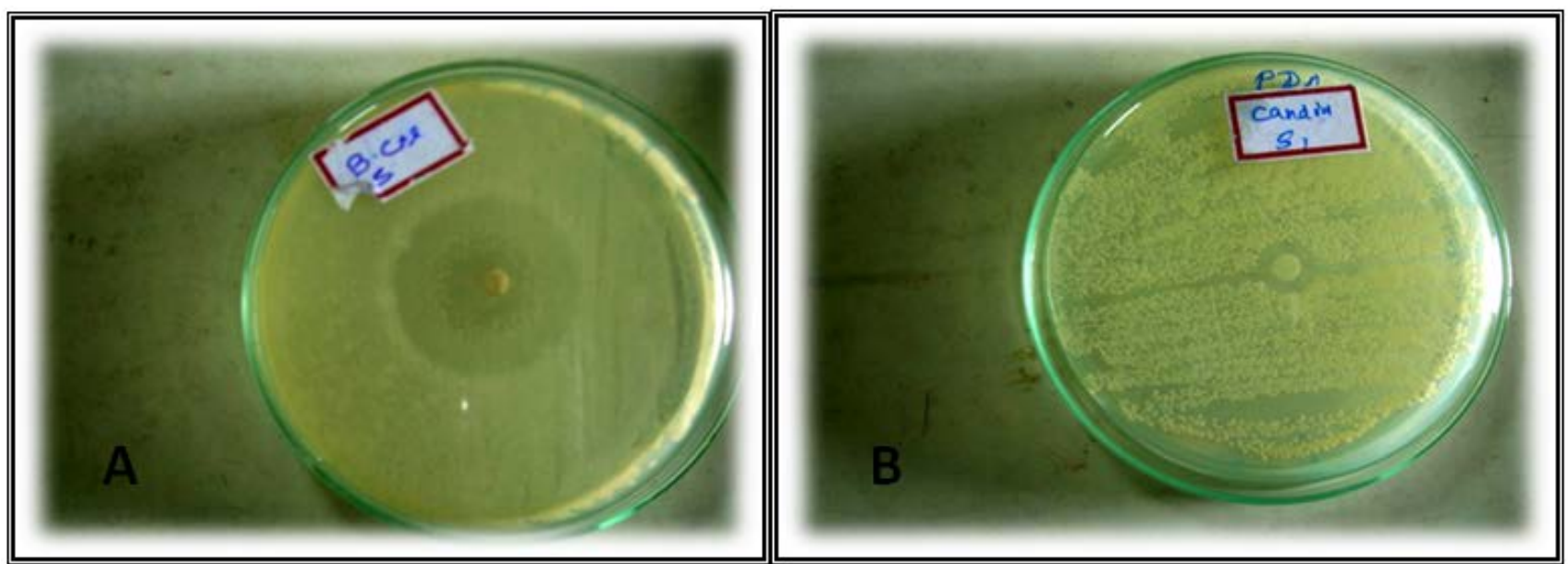

Figure 8. Zone of inhibition Ethanol leaf extract against A: B. cereus and B: C. albicans

\section{Plate - 2}

\section{Review Comment Answer}

1. Please mention whether the strain
Yes all the strain used were standard strain obtained from MTCC and some collected from Gujarat university microbiology laboratory detail is given below: 


\begin{tabular}{|l|l|}
\hline Organism & MTCC \\
\hline Escherichia coli & 4296 \\
\hline Bacillus megaterium & 4911 \\
\hline Bacillus cereus & 6629 \\
\hline Bacillus subtilis & 1134 \\
\hline Cornynebacterium glutamicum & \\
\hline Stephylococcus aureus & \\
\hline Aspergillus niger & 281 \\
\hline Salmonella typhi & \\
\hline Salmonella typhi A & \\
\hline Salmonella typhi B & \\
\hline Pseudomonas aeruginosa & 847 \\
\hline Proteus vulgaris & 426 \\
\hline
\end{tabular}

strains are collected from MTCC, Gujarat University microbiology dept and M.G.Science college ahmedabad, they are deposited in the biotech research lab of MUIS, Ganpat University.

2. Please make table of antibacterial /antifungal activity of standard drugs against tested organisms Yet this work has to be done ; its under progress.

3. Please show the antibacterial and antifungal activity of the extract linearly increase in concentration of extract as compared with standard drugs

This work also yet to be done. Its also under progress. 